\title{
The Issue and Risk Analysis of the Credit Card
}

\author{
Dhartee Ghawale, Pratiksha Gharde, Ashvini Bagade, N. Lakshmanan, Prof. Omkar Dudhbure
}

Manoharbhai Patel Institute of Engineering and Technology, Shahapur, Maharashtra, India

\begin{abstract}
Article Info

Volume 7, Issue 3

Page Number: 615-617

Publication Issue :

May-June-2021

\section{Article History}

In order to systematically evaluate credit card risk, opportunities for specific action and activity are used on paper. Based on the rapid development of the local credit card market, the current risks of the application and the issue of the credit card are discussed. With a credit card application using a credit card, a situation may arise where a customer may wish to repay the loan on time. In addition, the credit rating system, marketing and approval method, credit card overpayment, incentive orders and penalties, use management and other related angles are considered to solve the credit card risk problem.
\end{abstract}

Accepted : 10 June 2021

Published : 16 June 2021
Keywords - Probability, Rapid Development, Potential Risk, Repay The Loan.

\section{INTRODUCTION}

Risk credit losses due to non-payment of loans or other credit lines .the bank should be aware of the need to identify rates, monitor and control debt, and risks as well . Credit card also to determine if they have enough money to deal with these risks and that they are good enough. Management Effective credit risk management is an important component of pressure. Access to risk management and is essential for the long-term success of any financial institution. Analysis is a method by which one can calculate the creditworthiness of a business or organization.

Many customers are their model. Credit card to determine the levels of potential customers and those at risk.Debt that has been growing rapidly in recent years. Due to business interest and high profitability, credit card services have become a point business and have become one of the most important sources of banking profit.
In credit card testing there are 3 algorithm used namely

1. Declaration Category ('dt')

2. K Neighbor Separator ('knn')

3. Random forest layout ('rf')

\section{LITERATURE REVIEW}

The previous studies have been incorporated that deal with credit card default prediction using imbalanced data. Multiple combinations such as 'machine learning and credit card default prediction' and 'credit card default prediction and imbalanced data' have been used to retrieve the journal papers and conference proceedings [04].Three databases, namely IEEE Xplore, ScienceDirect, and SpringerLink, have targeted. In total, 400 articles were retrieved, and 150 duplicated items were removed [06].The title and abstract were screened to

Copyright: @ the author(s), publisher and licensee Technoscience Academy. This is an open-access article distributed under the terms of the Creative Commons Attribution Non-Commercial License, which permits unrestricted non-commercial use, distribution, and reproduction in any medium, provided the original work is properly cited 
identify potential articles.The full texts of 100 studies were assessed to find the relevancy with the inclusion criteria [09].The articles that were related to the loan prediction through images, corporate default prediction, and credit card threats prediction have excluded. In total, 30 studies were finally selected for data utilization purposes [03]. The previous review articles were also used in addition to these included papers to provide a comprehensive performance evaluation .[02]

Not only is the plastic money in circulation in India falling, it is also underutilized. On an average, the annual number of transactions per credit cards stands at 11 ; it is only one in case of debit cards. "Debit cards have had a slow start and their growth only took off in the last three years. On the other hand, credit cards grew faster since inception, with the growth turning negative in the latest year, [1] There is security risk in using credit card. This type of risk is experienced around the world. For example: The most common type of credit card fraud stems from lost or stolen cards or card numbers, which can lead to the thief using the card or card number for criminal purposes over the telephone or the Internet (card-not present purchases)[05].

"Skimming," account number generation, hacking, Card Verification Value (CVV), a three-to-four digit number that is printed (not embossed) on the back or front of all Unissued credit cards [02]. A newer type of credit card fraud, called "phishing," occurs when a victim is solicited via e-mail to visit a sham website of a "trusted institution" to "confirm or renew" private account information. [07].

\section{METHOLOGY}

In this section, we explained the methodology of our study. Three imbalanced datasets have been employed to build a model for the effective prediction of credit default clients. After that, the data has been preprocessed to achieve effective results because real-world data leads to noisy values. Furthermore, to cater to the data imbalance problem, different resampling methods have been utilized to get the best results. After preprocessing, a Gradient Boosted Decision Tree (GBDT) model, which is an ensemble-based learning method, has been used for modeling and also compared the results with traditional machine learning models. At last, the credit default prediction model has been deployed for the end-users to predict the default risk earlier effectively. The proposed method is also explained in Figure 1. The following hypotheses have been developed to validate the significance of the proposed method.

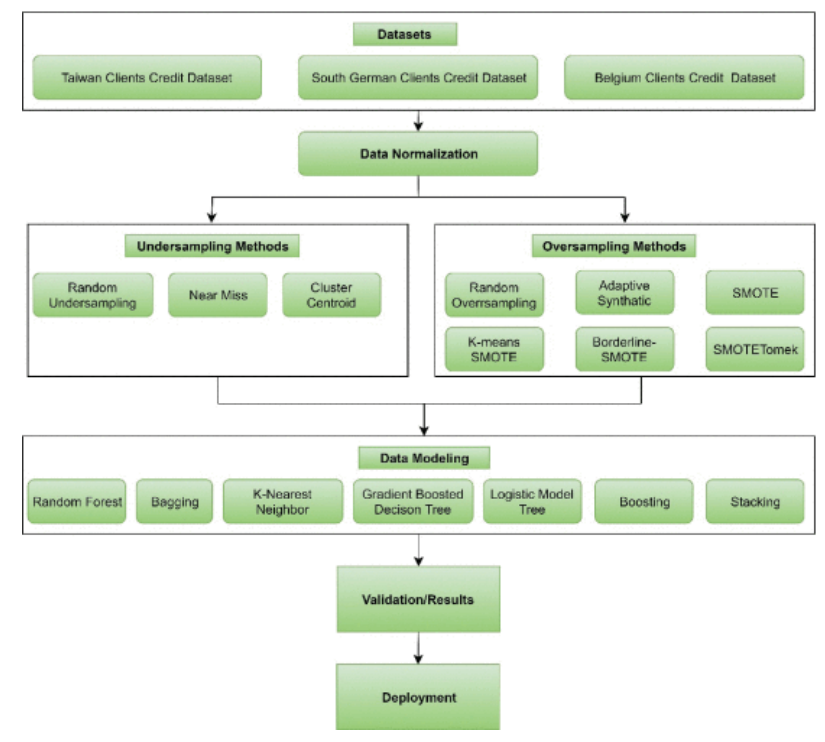

FIGURE 1. Proposed methodology

First Null Hypothesis ( $\mathrm{HO}$ ): There is no difference in the performance of various machine learning techniques.

Alternative Hypothesis (H1): The improvement of performance by our developed model statistically significantly better.

Second Null Hypothesis (H0): The use of imbalanced techniques do not improve the performance of the models. 
Alternative Hypothesis ( $\mathrm{H} 1$ ): The use of imbalanced techniques significantly improves the performance of the models.

\section{CONCLUSION}

This paper introduces SVM's novel approach to debt consolidation. The development of the SVM-based merger model according to the evaluation process, the artistic result revealed among the most commonly used types of credit risk verification, Addition In addition, this study also has a specific question for future study studies for the first time the performance of the integration work parameter based on our proposed process can be further investigated. It is very helpful to combine the conclusion with various forms of credit.

\section{REFERENCES}

[1]. T.A.Durkin, "Long-run credit growth in the US,"Journal of economics and business,vol.62,2010,pp.383-400.

[2]. X.Y.Sun, "The impression on banks and customers of Amecican credit card's new law,"China finance,July 2009,pp.62-63.

[3]. Network download.General operation of payment system in 2010 and 1st,2011.

[4]. Network download.Chinese credit card industry development blue book in 2009.

[5]. Drafting group of 'Commercial bank's credit card business management and supervision measures', “Six keywords of 'Commercial bank's credit card business management and supervision measures',"China credit card,vol.3,2011,pp.15-17.

[6]. Lili Wang, "Demographics,attitude,personality and credit card features correlate with credit card debt,"Journal of economic psychology,February 2011,pp.179-193.
[7]. S.R.Sun, "Mathematical model of institution for behavior controls and the strengh level of the institution,"Jounal of systems engineering,April 2008,pp.228-232.

[8]. J.Z.Yan, "Game analysis of personal credit behavior,",Commercial research,November 2007,pp.21-24.

[9]. Li Shen, "The theoretical and empirical analysis on the competition of Chinese credit card market ,’Journal of financial research,vol.4,2010,pp.191-206.

\section{Cite this article as :}

Dhartee Ghawale, Pratiksha Gharde, Ashvini Bagade, N. Lakshmanan, Prof. Omkar Dudhbure, "The Issue and Risk Analysis of the Credit Card", International Journal of Scientific Research in Computer Science, Engineering and Information Technology (IJSRCSEIT), ISSN : 2456-3307, Volume 7 Issue 3, pp. 615-617, May-June 2021. Available at doi $\quad$ : https://doi.org/10.32628/CSEIT2173122

Journal URL : https://ijsrcseit.com/CSEIT2173122 